Revue d'histoire de l'Amérique française

Q REVUE D.HISTOIRE DE L'AMÉRIQUE FRANÇAISE

\title{
IACOVETTA, Franca et Mariana VALVERDE, dir., Gender Conflicts. New Essays in Women's History. Toronto, University of Toronto Press, 1992. 303 p. 16,95 \$
}

\section{Nathalie Kermoal}

Volume 47, numéro 3, hiver 1994

URI : https://id.erudit.org/iderudit/305273ar

DOI : https://doi.org/10.7202/305273ar

Aller au sommaire du numéro

Éditeur(s)

Institut d'histoire de l'Amérique française

ISSN

0035-2357 (imprimé)

1492-1383 (numérique)

Découvrir la revue

Citer ce compte rendu

Kermoal, N. (1994). Compte rendu de [lACOVETTA, Franca et Mariana VALVERDE, dir., Gender Conflicts. New Essays in Women's History. Toronto, University of Toronto Press, 1992. 303 p. 16,95 \$]. Revue d'histoire de l'Amérique française, 47(3), 463-464. https://doi.org/10.7202/305273ar d'utilisation que vous pouvez consulter en ligne.

https://apropos.erudit.org/fr/usagers/politique-dutilisation/ 
IACOVETTA, Franca et Mariana VALVERDE, dir., Gender Conflicts. New Essays in Women's History. Toronto, University of Toronto Press, 1992. 303 p. $16,95 \$$

Il n'est plus besoin de présenter l'importance et l'utilité d'écrire l'histoire des femmes au Canada. Les historiennes s'intéressent constamment à l'élaboration de nouvelles approches méthodologiques, à l'utilisation de nouvelles sources et à trouver les réponses à de nouvelles questions. 
Le livre, Gender Conflict. New Essays in Women's History, paru sous la direction de Franca Iacovetta et Mariana Valverde, se situe dans cette nouvelle lignée du travail historique. Les huit articles rassemblés dans cet ouvrage sont une sorte de rétrospective de ce qui se fait de mieux en histoire des femmes aujourd'hui.

Ces textes, tous aussi passionnants les uns que les autres, explorent les différentes facettes de la vie des femmes en Ontario aux $\mathrm{XIX}^{\mathrm{e}}$ et $\mathrm{XX}^{\mathrm{e}}$ siècles. $\hat{A}$ travers des thèmes comme la religion, le travail, la politique, le monde des affaires et de la consommation, la vie intellectuelle, la loi et l'émigration, les auteures explorent les tensions qui pouvaient exister entre les hommes et les femmes, mais surtout entre les femmes d'ethnie, de culture et de classe différentes. C'est ce qu'elles appellent «Gender Conflicts».

L'histoire des femmes n'est pas figée et l'expérience féminine dépasse le domaine de la famille et du travail. En effet, pendant trop longtemps, l'histoire des femmes a eu une fâcheuse tendance à explorer la vie des femmes dans leurs sphères traditionnelles sans pour autant intégrer les expériences d'immigrantes, de travailleuses ou remettre en question les théories féministes d'une Emily Murphy basées sur le racisme.

Le livre Gender Conflicts. New Essays in Women's History posent ces problèmes et en développent bien d'autres encore. Mais tout dévoiler relèverait du "péché» car les lecteurs et les lectrices n'auraient plus rien à découvrir. Ce recueil d'articles est précurseur d'un nouveau mouvement qui devrait pousser les historiennes du Canada français et du Canada anglais à aller plus loin dans leurs interrogations sur l'histoire des expériences féminines.

Faculté Saint-Jean

Université de l'Alberta

NATHALIE KERMOAL 